\title{
Screening older patients for obstructive airways disease in a semi-rural practice
}

\author{
J A Dickinson, M Meaker, M Searle, G Ratcliffe
}

\begin{abstract}
Background-Obstructive airways disease in older patients is reported to be not only common, but frequently overlooked and untreated by general practitioners. This study examines the value of screening elderly patients in a large semi-rural general practice for potentially treatable asthma and chronic obstructive pulmonary disease (COPD).

Methods-A random sample of 353 patients aged 60-75 years attended a nurse run screening clinic for pulmonary function testing, serial peak flow recording, and completion of a symptom questionnaire. Patients with a low forced expiratory volume in one second (below the fifth centile of their predicted value) or $>15 \%$ mean diurnal variation in peak flow were referred to a doctor's clinic for further diagnostic assessment and/or to discuss possible treatment where appropriate.

Results-Fifty eight patients $(16.4 \%)$ had obstructive airways disease, the prevalence of asthma being $6.5 \%$ and that of COPD $9.9 \%$. Of these, 30 had no previous diagnosis of airways disease and were not on treatment; eight of them had significant airways reversibility and 10 were current smokers. No newly diagnosed patients had severe disease as measured by pulmonary function or quality of life assessment, and six patients accepted treatment.

Conclusion-Few older patients benefited from a screening programme for obstructive airways disease in a semi-rural general practice.

(Thorax 1999;54:501-505)
\end{abstract}

Keywords: asthma; chronic obstructive pulmonary disease; screening; geriatrics; general practice

Central Surgery, King

Street, Barton on

Humber, North

Lincolnshire

DN18 5ER, UK

J A Dickinson

M Meaker

M Searle

G Ratcliffe

Correspondence to: Dr J A Dickinson.

Received 1 June 1998 Returned to authors 27 July 1998

Revised manuscript received

26 January 1999

Accepted for publication

29 January 1999
The prevalence of asthma and chronic obstructive pulmonary disease (COPD) has been likened to an iceberg with the submerged undiagnosed portion representing two thirds of the whole. ${ }^{1}$ Underdiagnosis is said to be particularly common in older patients because of multiple pathology, difficulty with measurement of lung function, under-reporting of symptoms, ${ }^{2}$ and reduced perception of dyspnoea. $^{3}$ The British Thoracic Society's guidelines on asthma management ${ }^{4}$ refer to frequent underdiagnosis in the elderly, and the COPD guidelines ${ }^{5}$ point to a substantial unmet need. Two surveys in the United Kingdom ${ }^{67}$ not only found that chronic airways obstruction is common and frequently overlooked, but that most patients would have benefited from appropriate treatment. Therapeutic nihilism on behalf of the doctors was one suggested explanation.

This is the first comparable study to be carried out in a British general practice. We surveyed a random sample of older patients (aged 60-75) in a small town in North Lincolnshire to determine how many patients had undiagnosed obstructive airways disease, what proportion had significant reversibility, and in how many was treatment appropriate or acceptable.

\section{Methods}

This seven partner general practice serves a population of 15200 patients in a mixed rural and urban area of North Lincolnshire of whom 2602 are aged between 60 and 75 years. The doctors have personal lists and the practice runs three nurse held asthma clinics per week. The number of drugs prescribed by the practice for all respiratory illnesses is 3\% below the average for the local health authority. ${ }^{8}$

\section{POPULATION SAMPLING}

A random sample of 500 patients aged $60-74$ years from a total of 1175 living within the town of Barton were identified using computer generated random numbers and invited to a health assessment clinic run by the health visitor. The author's patients (JAD) were not included as they had already been screened in a pilot study.

HEALTH ASSESSMENT CLINIC

Screening of respiratory symptoms and pulmonary function were part of a wider assessment. The health visitor also offered individuals the opportunity to discuss any concerns they might have and took the opportunity to promote health by discussion about lifestyles. Height, weight, and blood pressure were measured and a urine sample tested for sugar and protein.

\section{RESPIRATORY ASSESSMENT BY THE HEALTH}

VISITOR

A simple non-validated questionnaire on current respiratory symptoms (cough, wheezing, and shortness of breath), details of previous respiratory diagnoses, and smoking history was completed by each patient. Details of any acute illness in the previous four weeks were recorded as they might have affected any measure of pulmonary function. Respiratory function tests were carried out on a portable Escort spirometer (Vitalograph Ltd, Buckingham, UK) which was in regular use in the asthma clinic and therefore familiar to the nurses. The 


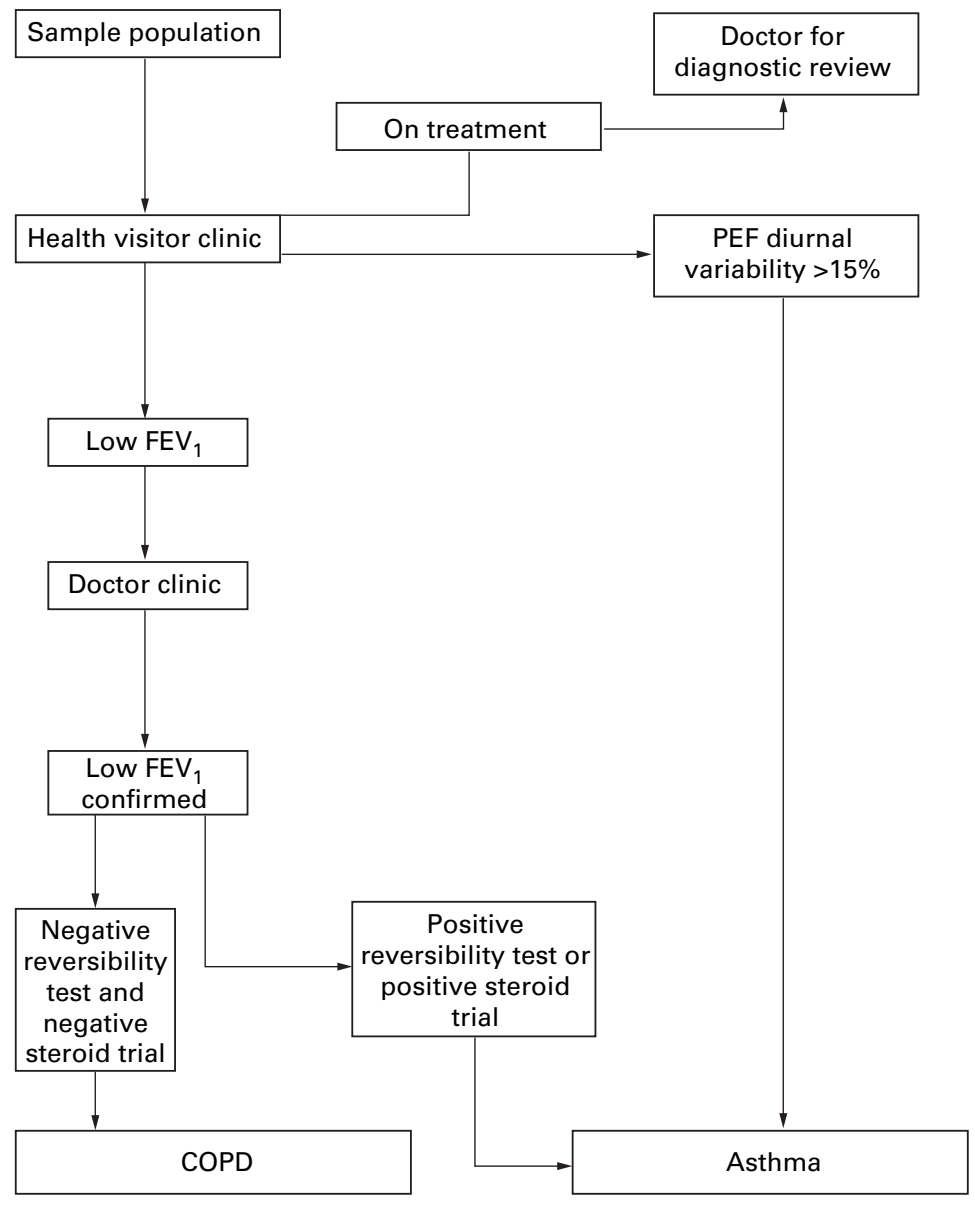

Figure 1 Diagnostic algorithm for COPD and asthma in general practice.

instrument was set for the ambient temperature and calibrated with a one litre syringe at each session. After sufficient instruction each subject was asked to perform three forced expiratory manoeuvres from maximum inspiration and the best value for forced expiratory volume in one second $\left(\mathrm{FEV}_{1}\right)$ was recorded. Patients were then shown how to measure their peak expiratory flow (PEF) using a mini peak flow meter (Clement Clark) and asked to record the best of three readings taken morning and evening for 10 days. Our pilot study had found that older patients had difficulty reading a standard chart, and there was a frequent pattern of erratic and usually low recordings during the first three days which probably reflected the period when the patient was learning the technique. We therefore analysed the last seven days only on an enlarged chart.

Patients with a low $\mathrm{FEV}_{1}$ were referred to a doctor's clinic for further diagnostic assessment, and those with asthma diagnosed by significant diurnal variation of peak flow were referred to discuss possible treatment options.

DOCTOR ASSESSMENT CLINIC

A detailed medical history and examination was carried out with special reference to the respiratory system, cardiac problems, and current drug usage. Recordings of $\mathrm{FEV}_{1}$ and forced vital capacity (FVC) were repeated on a Vitalograph dry bellows spirometer and volumes were expressed in BTPS. Recordings were repeated until three satisfactory tracings had been obtained within $5 \%$ of each other. Analysis was based on the highest $\mathrm{FEV}_{1}$ and FVC for the three tracings. Reversibility testing was carried out by repeating the $\mathrm{FEV}_{1}$ measurement 15 minutes after the inhalation of $400 \mu \mathrm{g}$ salbutamol through a large volume spacer (Volumatic, Allen \& Hanbury Pharmaceuticals). All patients completed the respiratory impact section of the St George's Respiratory Questionnaire. ${ }^{9}$

A steroid trial was offered to those patients who had a significantly reduced $\mathrm{FEV}_{1}$, a negative reversibility test, and a score on the respiratory questionnaire corresponding to moderate or severe disease. Patients with newly diagnosed asthma confirmed by significant diurnal variation in PEF had a drug review and reversibility testing with salbutamol before treatment was considered.

All untreated patients with a new diagnosis of asthma or COPD had an extended consultation in which the results of the tests were explained and treatment options discussed. Prescriptions and follow up appointments were issued where appropriate, current smokers were offered referral to a smoking cessation clinic, and all patients were advised to have an influenza vaccination.

The records of patients already on treatment for asthma or COPD were reviewed for evidence of diagnostic tests. Where these were lacking or inconclusive the patients were seen at the clinic for assessment to ensure that the overall figures for the incidence of the two conditions were as accurate as possible. A change in diagnostic label did not result in inclusion in the figures for newly diagnosed disease.

\section{DIAGNOSIS}

Chronic obstructive airways disease was diagnosed using the criteria of Van Shayck et $a l^{10}$-namely, an $\mathrm{FEV}_{1}$ lower than the predicted value minus $840 \mathrm{ml}$ in men and $620 \mathrm{ml}$ in women (representing the fifth centile) with a change in $\mathrm{FEV}_{1}$ of $<9 \%$ of the predicted value after administering $400 \mu \mathrm{g}$ salbutamol. For patients aged 60-70 years the reference values established by the European Respiratory Society ${ }^{11}$ were used, whereas for patients over 70 years the predicted values of the Cardiovascular Health Study on patients aged 65-85 years ${ }^{12}$ were preferred since the European sample had few patients in this age group.

Asthma was diagnosed by the presence of one or more of the following criteria: (1) a diurnal variability in PEF (highest minus lowest peak flow divided by the highest) of more than $15 \%$, (2) a change in $\mathrm{FEV}_{1}$ of $9 \%$ or more compared with the predicted value after administering $400 \mu \mathrm{g}$ salbutamol, and (3) a rise in baseline peak flow of $15 \%$ or more after $40 \mathrm{mg}$ prednisolone daily for 14 days or inhaled beclomethasone $500 \mu \mathrm{g}$ twice daily for six weeks.

A diagnostic algorithm is shown in fig 1 .

\section{Results}

Of 500 subjects contacted, nine died and six left the area during the course of the study. Of 
Table 1 Details of subjects with obstructive airways disease

\begin{tabular}{llrll}
\hline & Total $(n=353)$ & Men & Women & $\begin{array}{l}\text { On treatment } \\
\text { before study }\end{array}$ \\
\hline Obstructive airways disease & $58(16.4 \%)$ & 26 & 32 & 28 \\
Asthma & $23(6.5 \%)$ & 8 & 15 & 15 \\
COPD & $35(9.9 \%)$ & 18 & 17 & 13 \\
\hline
\end{tabular}

COPD $=$ chronic obstructive pulmonary disease.

Table 2 Presence of symptoms (cough, wheeze and dyspnoea) and smoking history

\begin{tabular}{lrrrrr}
\hline & No. & \multicolumn{1}{c}{ Symptoms } & $\begin{array}{l}\text { Never } \\
\text { smoked }\end{array}$ & Ex-smoker & \multicolumn{1}{c}{$\begin{array}{l}\text { Current } \\
\text { smoker }\end{array}$} \\
\hline Asthma & 23 & $7(30.4 \%)$ & $8(34.8 \%)$ & $9(39.1 \%)$ & $6(26.1 \%)$ \\
COPD & 35 & $27(77.1 \%)$ & $1(2.9 \%)$ & $21(60 \%)$ & $13(37.1 \%)$ \\
Restrictive disease & 3 & $3(100 \%)$ & $1(33.3 \%)$ & $2(66.6 \%)$ & 0 \\
Normal spirometry and PEF & 292 & $126(43.2 \%)$ & $125(42.8 \%)$ & $130(44.5 \%)$ & $37(12.7 \%)$ \\
Total & 353 & $163(46.2 \%)$ & $135(38.2 \%)$ & $162(45.8 \%)$ & $56(15.9 \%)$ \\
\hline
\end{tabular}

$\mathrm{COPD}=$ chronic obstructive pulmonary disease $\mathrm{PEF}=$ peak expiratory flow.

the remaining 485 patients $392(81 \%)$ attended the health visitor clinic. Thirty four subjects declined, failed to return, or were judged unable to carry out home PEF recordings and five were unable to perform any pulmonary function tests. The remaining 353 subjects $(73 \%)$ form the study population (184 women; mean age 68 years 3 months).

\section{RECRUITMENT BIAS}

Ninety three patients (19\%), 47 of whom were women, of mean age 66 years 9 months declined two invitations to the clinic. Examination of their medical records revealed that nine $(10 \%)$ had a diagnosis of air flow obstruction of whom four were labelled asthma and five COPD. Five patients were housebound. Thirty $(88 \%)$ of the 34 patients who did not complete their peak flow records had normal spirometric test results.

INCIDENCE OF OBSTRUCTIVE AIRWAYS DISEASE Fifty eight subjects $(16 \%)$ had obstructive airways diseases (23 asthma, 35 COPD) of which 30 were newly diagnosed (eight asthma, 22 COPD; table 1).

Of those with normal spirometric test results and peak flow readings, $43 \%$ had one or more symptoms and $13 \%$ were current smokers compared with $30 \%$ and $26 \%$ for asthma and $77 \%$ and $37 \%$ for COPD, respectively (table 2).

Forty nine patients were seen at the doctor's clinic of whom 14 with a low $\mathrm{FEV}_{1}$ on initial testing were found to have normal values at the assessment clinic, three of whom had a concurrent respiratory illness when first seen.

\section{NEWLY DIAGNOSED OBSTRUCTIVE AIRWAYS}

DISEASE

A new diagnosis of asthma was made in eight patients (five had a diurnal variation of $>15 \%$, two had a positive reversibility test with salbutamol, and one had an attack of acute asthma requiring steroids and nebulised $\beta$ agonist before attending the clinic). None of the patients with significant diurnal variation had a positive reversibility test with salbutamol. Five patients accepted treatment.

Two patients fulfilled the criteria for a steroid trial, both of which were negative. A diagnosis of COPD was made in 22 patients. The sever- ity judged by the $\mathrm{FEV}_{1}$ as a percentage of predicted, as defined by the British Thoracic Society guidelines, ${ }^{5}$ was mild in 12 and moderate in 10 patients. Scores on the respiratory impact questionnaire were normal in 16, mild in five, and moderate in one. No patients had severe disease on either measurement and one patient accepted treatment.

Six of the newly diagnosed patients with COPD and four with a new diagnosis of asthma were current smokers. None wished to attend a smoking cessation clinic but 12 months after attending the study assessment three reported that they had stopped smoking. The screening clinics took 330.5 hours of nurses' time and approximately half of this was spent on respiratory assessment. The doctors' clinics took 18 hours. Sixty three patients were referred to their general practitioner because of other abnormal findings (40 with blood pressure in excess of $160 / 100,11$ with glycosuria, and 12 with proteinuria).

\section{Discussion}

The overall prevalence of obstructive airways disease was $16.4 \%$ with asthma having a prevalence of $6.5 \%$ and COPD of $9.9 \%$. Comparison with other studies is bedevilled by problems of definition and exclusion of elderly patients. The studies from Finland by Isoaho et al investigated respiratory disease in the elderly and reported a prevalence of asthma of $2.9 \%$ in men and $3.8 \%$ in women, ${ }^{13}$ with a prevalence of COPD in men of $12.5 \%$ and in women of $3 \% .{ }^{14}$ They found a high incidence of undiagnosed disease and advocated screening of middle aged and elderly patients by spirometric testing and symptom assessment. In contrast, a large Dutch screening programme ${ }^{1}$ found no undiagnosed severe disease and concluded that there was no evidence that early and preventive care would improve long term outcome.

As in the Dutch study, we found no evidence of significant untreated disease. Six per cent of the patients had undiagnosed COPD, but none were severe as measured by pulmonary function or the respiratory impact questionnaire. The absence of undiagnosed severe disease is unlikely to be due to increased awareness as none of the doctors of the examined patients had a particular interest in respiratory medicine, and the number of prescriptions used by the practice for respiratory drugs is below the average for the local health authority. Two per cent of patients had undiagnosed asthma and five accepted treatment.

COMPARISON WITH OTHER UK STUDIES

Two studies in the $\mathrm{UK}^{67}$ found a high prevalence of undiagnosed obstructive airways disease in an elderly population, many of whom had significant airways reversibility. Renwick and Connolly ${ }^{7}$ concluded that most patients so diagnosed were not receiving appropriate treatment either due to tolerance of respiratory symptoms by elderly people or therapeutic nihilism on behalf of their doctors. Both suggested a large burden of unmet need in older patients. Banerjee et $a l^{6}$ studied a population of elderly patients (mean age 78 years) 
who were either attending a day hospital or living in residential care and were therefore likely to have had a higher incidence of morbidity than a random sample. They found $61 \%$ of 199 subjects had a PEF less than $70 \%$ predicted, of whom $67 \%$ showed significant reversibility ( $15 \%$ from base to $200 \mu \mathrm{g}$ salbutamol). Only $6 \%$ were receiving respiratory related medication.

The 247 randomly selected patients from central Manchester studied by Renwick and Connolly were of a similar age (mean 66 years 1 month) and spirometric evidence of obstructive airways disease was found in $26.4 \%$ of them, $54 \%$ of whom had either increased nonspecific bronchial responsiveness or significant reversibility. We found a smaller prevalence of obstructive airways disease $(16.4 \%)$ than either of these studies. The proportion already diagnosed $(48 \%)$ was similar to that of Renwick and Connolly (55\%), while the proportion with significant reversibility (40\%) was smaller than that of Banerjee et al. These differences may be due in part to the variety of diagnostic criteria used. There is some evidence of a greater incidence of obstructive airways disease in an urban population ${ }^{15}$ and in lower socioeconomic groups. ${ }^{16}$ Devereux et $a l^{17}$ were unable to demonstrate any difference in airway responsiveness or other parameters of diagnostic relevance to asthma between a rural and inner city population. A recent nationwide study of asthma in children found little regional variation. ${ }^{18}$

The number of current smokers in our sample was lower than that of the Manchester study $(15.9 \%$ versus $29.2 \%)$ while the proportion who had never smoked was slightly higher $(38.2 \%$ versus $33.5 \%)$.

DIAGNOSIS

The diagnostic criteria used in this study were based on those of the European Primary and Secondary Care Respiratory Specialist Working Group in which interpretation of spirometric variables relies on absolute values rather than percentage predicted. The use of the former was preferred in this study of the elderly as there is evidence that percentage predicted values become less accurate with age. ${ }^{11} 19$ The interpretation of bronchodilator response using percentage predicted values rather than percentage of the initial $\mathrm{FEV}_{1}$ was preferred as the latter is more dependent on the initial $\mathrm{FEV}_{1}$ and may result in spurious positive results in those patients with severe initial airways obstruction. $^{20}$

Diurnal variation of PEF was calculated using the amplitude percentage of the highest reading as this is the method most commonly used in the UK and preferred by the UK Asthma Training Centre. ${ }^{21}$ Home recording of PEF was successfully carried out by $90 \%$ of patients attending the screening clinic. None of the five patients with abnormal diurnal variation of PEF showed significant reversibility to inhaled salbutamol. Reversibility to a bronchodilator is a relatively insensitive test in making a diagnosis of asthma. ${ }^{22-24} \mathrm{~A}$ recent study has shown that twice daily PEF readings may underestimate the incidence of diurnal variation and suggests a minimum of four daily readings. ${ }^{25}$

The finding that 14 patients with a low FEV on nurse testing subsequently had normal results may have been due to acute illness during initial testing (three cases), difficulty performing the test due to advancing years, or the lack of display of flow-volume curve in the portable spirometer.

SCREENING FOR OBSTRUCTIVE AIRWAYS DISEASE Comprehensive assessment of pulmonary function is time consuming and expensive. Initial screening of respiratory function in 392 patients took 165 nurse hours and a more detailed assessment took 18 hours of the doctors' time. Attempts have been made to detect elderly patients with treatable respiratory disease by means of a symptom questionnaire. Respiratory symptoms are very common in the elderly, however, and were present in $43.2 \%$ of our patients with normal pulmonary function. Dow et $a l^{26}$ were unable to identify patients with a bronchial irritability syndrome described by Mortagy ${ }^{27}$ in younger patients. In an earlier study ${ }^{28}$ we were unable to identify older patients with asthma using a validated questionnaire.

Our screening programme for undiagnosed obstructive airways disease failed to confirm the large burden of unmet need described in previous UK studies and does not support the creation of specific screening clinics for respiratory disease in the elderly. The addition of spirometric tests to a comprehensive health screen for older people is probably justified. Although mainly mild COPD is likely to be identified, these patients may benefit from advice on smoking, influenza (and possibly pneumococcal) immunisation, and future monitoring of pulmonary function. We should beware, however, of equating disease with illness. Most newly discovered patients with abnormal pulmonary function did not perceive themselves as handicapped nor welcome treatment. The place of serial peak flow recordings is debatable. We found the test valuable in diagnosing asthma and well accepted, but it does require considerable effort on the part of the patient in both carrying out the test and returning the results.

There is a need for a quick, reliable, and safe test for inflammatory lung disease which could be combined with spirometric testing in a screening clinic.

The authors thank Drs K Jones, M Levy and Mr T Turner for their advice. JAD and MM conceived and co-ordinated the project. JAD wrote the first draft. GR and MS participated in the execution of the study, and MS collected the data. Funding: Glaxo Welcome UK Ltd.

Conflict of interest: none.

1 Tirimanna PRS, Van Schayck CP, den Otter JJ, et al. Prevalence of asthma and COPD in general practice: has it changed since 1977? Br F Gen Pract 1996;46:277-81.

2 Dow L, Coggon D, Campbell MJ, et al. The interaction between immunoglobulin $\mathrm{E}$ and smoking in airflow obstruction in the elderly. Am Rev Respir Dis 1992;146: 402-7.

3 Connolly MJ, Crowley JJ, Charan NB, et al. Reduced subjective awareness of bronchoconstriction provoked by metacholine in elderly asthmatic, and normal subjects as measure on a simple awareness scale. Thorax 1992;47:410 3. 
4 British Thoracic Society, et al. The British guidelines on asthma management: 1995 review and position statement. Thorax 1997;52(Suppl 1):S1-21.

5 British Thoracic Society, et al. The British guidelines for the management of chronic obstructive pulmonary disease. Thorax 1997;52(Suppl 5):S1-28.

6 Banerjee DK, Lee GS, Malik SK, et al. Underdiagnosis of asthma in the elderly. Br f Dis Chest 1987;81:23-9.

7 Renwick DS, Connolly MJ. Prevalence and treatment of chronic airways obstruction in adults over the age of 45 Thorax 1996;51:164-8.

8 PACT Standard Report. Prescription Pricing Authority. Quarter ending December 1996

9 Jones PW, Quirk FH, Baveystock CM, et al. A self complete measure of health status for chronic airflow limitation. The St George's Respiratory Questionnaire. Am Rev Respir Dis 1992;145:1321-7.

10 Van Schayck CP. Primary and secondary care respiratory specialists working group. Diagnosis of asthma and chronic specialists working group. Diagnosis of asthma and chronic obstructive pulmonary
Pract 1996;46:193-7.

11 Qanjer Ph H, Tammeling GJ, Cotes JE, et al. Lung volumes and forced ventilatory flows. Official statement of the European Respiratory Society. Eur Respir f 1993;6(Suppl 16):5-40

12 Enright PL, Kronmal RA, Higgins M, et al. Spirometry reference values for women and men 65 to 85 years of age. Cardiovascular Health Study. Am Rev Respir Dis 1993;147: 125-33.

13 Isoaho R, Puolijoki H, Huhti E, et al. Prevalence of asthma in elderly Finns. F Clin Epidemiol 1994;47:1109-18.

14 Isoaho R, Puolijoki H, Huhti E, et al. Prevalence of chronic obstructive pulmonary disease in elderly Finns. Respir Med 1994;88:571-80.

15 Tashkia DP, Detels R, Simmons M, et al. The UCLA population study of chronic obstructive respiratory disease: impact of air pollution and smoking on annual change in $\mathrm{FEV}_{1}$. Am $\mathcal{F}$ Respir Crit Care Med 1994;149:1209-17.

16 Pride NB. Smoking and the development of progressive airflow obstruction. Ann Acad Med Singapore 1985;14:496502
17 Devereux G, Ayatollahi T, Ward R, et al. Asthma, airways responsiveness and air pollution in two contrasting districts of Northern England. Thorax 1996;51:169-74.

18 Kaur B, Anderson HR, Austin J, et al. Prevalence of asthma symptoms, diagnosis, and treatment in 12-14 year old children across Great Britain (International Study of Asthma and Allergies in Childhood, ISAAC UK). BMf 1998;316: 118-24.

19 Tweedale PM, Alexander F, McHardy GJR. Short term variability in $\mathrm{FEV}_{1}$ and bronchodilator responsiveness in patients with obstructive ventilatory defects. Thorax 1987;42:87-9.

20 Brand PLP, Quanjer PH, Potma DS, et al. Interpretation of bronchodilator response in patients with obstructive airways disease. Thorax 1992;47:429-36.

21 National Asthma Training Centre. Simply asthma. 1995

22 Connolly MJ, Kelly C, Walters EH, et al. An assessment of metacholine inhalation tests in elderly asthmatics. Age Ageing 1998;17:123-8.

23 Taylor RD. Making the diagnosis of asthma. BMF 1997;315: 4-5.

24 Prior JG, Cochrane GM. Assessment of optimum dose of inhaled terbutaline in patients with chronic asthma. The use of simple cumulative dose response curves. $\mathrm{Br} F \mathrm{Dis}$ Chest 1982;72:266-8.

25 Gannon PFG, Newton DT, Paatin CFA, et al. Effect of the number of peak expiratory flow readings on the estimate of diurnal variation. Thorax 1998;53:790-2.

26 Dow L, Coggon D, Holgate ST. Respiratory symptoms as predictors of airways lability in an elderly population. Respir Med 1992;86:27-32.

27 Mortagy AK, Howell JBL, Waters WE. Respiratory symptoms and bronchial reactivity: identification of a syndrome and its relation to asthma. BMF 1986;293:525-9.

28 Sutton $M$. An assessment of the usefulness of a respiratory symptoms questionnaire as an aid to diagnosing asthma in older people. MSc dissertation, Institute of Nursing Studies, University of Hull, 1994. 